\title{
Systemic Inflammatory Markers for Prediction of Bevacizumab Benefit in Glioblastoma Multiforme
}

\author{
Mehmet Besiroglu ${ }^{1}$, Abdallah TM Shbair ${ }^{1}$, Ayse Irem Yasin ${ }^{1}$, Atakan Topcu ${ }^{1}$, Haci Mehmet Turk ${ }^{1}$ and Tarik Demir ${ }^{2}$ \\ ${ }^{1}$ Department of Medical Oncology, Bezmialem Vakif University, School of Medicine Hospital, Istanbul, Turkey \\ ${ }^{2}$ Department of Medical Oncology, Haydarpaşa Numune Health Application and Research Center, Istanbul, Turkey
}

\begin{abstract}
Objective: To evaluate the predictive significance of systemic inflammation markers (SIMs) in patients with glioblastoma multiforme (GBM), who were treated with bevacizumab (Beva).

Study Design: Descriptive study.

Place and Duration of Study: The study was conducted at the Bezmialem Vakif University School of Medicine Hospital, Istanbul, Turkey, from January 2014 to September 2019.

Methodology: A total of 107 patients, 49 (45.8\%) female and 58 (54.2\%) male, were retrospectively included in the study. The cut-off values for the SIMs-C-reactive protein to albumin ratio (CAR), neutrophil to lymphocyte (NLR) platelet to lymphocyte ratio (PLR), and systemic immune-inflammatory index (SIII))-were defined by receiver operating characteristic (ROC) analysis. Overall survival (OS) was plotted using the Kaplan-Meier method and compared using the log-rank test. Cox regression analysis was performed for univariate and multivariate analyses.

Results: ROC analysis was performed to determine the optimal prognostic value of each parameter. CAR: 1.32, NLR: 2.9, PLR: 159, and SIII: 785 were determined as cut-off values for predicting OS based on the areas under the curve (AUC) in the ROC analysis. CAR at 0.626 , had sensitivity of $67 \%$, and specificity of $71 \%(p=0.129)$; NLR at 0.725 had sensitivity of $67 \%$, and specificity of 79\% ( $p=0.007)$; PLR at 0.675 had sensitivity of $67 \%$, and specificity of $64 \%(p=0.036)$; and SIII at 0.685 , had sensitivity of $56 \%$, and specificity of $71 \%(p=0.026)$. A multivariate analysis demonstrated that CAR $(p=0.006)$ and PLR $(p=0.024)$ were independent prognostic factors for OS in patients with GBM, treated by Beva.

Conclusion: The present study's findings suggest that pretreatment CAR and PLR might be an independent predictive marker for patients with GBM, who are treated by Beva.
\end{abstract}

Key Words: C-reactive protein-to-albumin ratio (AR), Glioblastoma multiforme, Neutrophil-to-lymphocyteratio (NLR), Platelet-to-lymphocyte ratio (PLR), Predictive score.

How to cite this article: Besiroglu M, Shbair AT, Yasin Al, Topcu A, Turk HM, Demir T. Systemic Inflammatory Markers for Prediction of Bevacizumab Benefit in Glioblastoma Multiforme. J Coll Physicians Surg Pak 2021; 31(01):39-44.

\section{INTRODUCTION}

More than half of central nervous system (CNS) tumors consist of grade 4 gliomas (glioblastoma multiforme, GBM), and the five-year overall survival (OS) varies between $1 \%$ and $19 \%$, depending on age. ${ }^{1}$ The primary treatment of GBM patients is gross total resection and adjuvant radiotherapy (RT) plus temozolomide (TMZ). ${ }^{2}$ In recurrent GBM patients, re-excision contributes to the survival of some patients. ${ }^{3}$ However, the disease eventually recurs despite all local treatments.

Correspondence to: Dr. Tarik Demir, Haydarpaşa Numune Health Application and Research Center, Istanbul, Turkey E-mail: dr.tarikdemir@hotmail.com

Received: September 14, 2020; Revised: December 18, 2020; Accepted: December 28, 2020

DOI: https://doi.org/10.29271/jcpsp.2021.01.39
Palliative systemic treatments are used in GBM patients for whom local treatments are not appropriate, but options are limited. TMZ is the only option in first-line systemic therapy, if the patient progresses after a long adjuvant interval. Options after TMZ are carmustine/lomustine, bevacizumab (Beva), and PVC. ${ }^{4}$

GBM is a tumor that shows high vascularity and expresses a very high rate of vascularendothelial growth factor (VEGF)-A. In addition, VEGF-A expression is associated with poor survival in GBM patients. ${ }^{5}$ Beva is a recombinant, humanised monoclonal antibody against VEGF-A and inhibits its interaction with VEGFR $1 / 2$ and neuropilins. ${ }^{6}$ Despite this, although Beva improved the quality of life and progression-free survival (PFS) in GBM patients, it did not contribute to OS. ${ }^{7}$ Many molecules and pathways related to the treatment resistance of Beva have been defined. Still, this issue has not yet been fully clarified, and, today, there is no established marker predicting Beva's response. ${ }^{8}$ However, the detection of Beva's predictive markers is vital for optimising individualised therapy. 
Many prognostic factors other than VEGF-A have been described in GBM patients, such as Karnofsky performance status (KPS) and age and genetic alterations including methylguanine-DNAmethyltransferase (MGMT), isocitratedehydrogenase (IDH), and telomerase reverse transcriptase (TERT). ${ }^{9}$ It has been shown that systemic inflammation markers (SIMs) are associated with a bad prognosis in other cancer types. ${ }^{10}$ However, prognosis studies of SIMs in GBM patients are inconsistent and have generally been investigated in patients receiving adjuvant therapy. ${ }^{11}$ Due to the role of neutrophil in neoangiogenesis in GBM patients, SIMs may be an important prognostic and predictive factor. ${ }^{12}$ Interestingly, the relationship between Beva treatment responses and SIMs in GBM patients has not been adequately studied.

In this study, the purpose was to evaluate the predictive importance of SIMs such as neutrophil to lymphocyte ratio (NLR), platelet to lymphocyte ratio (PLR), C-reactive protein (CRP) to albumin ratio (CAR), and systemic immune-inflammatory index (SIII) in GBM patients receiving Beva treatment.

\section{METHODOLOGY}

In this descriptive study, archived records between January 2014 and September 2019 for all GBM patients in Bezmialem Vakif University Hospital, Turkey, were used. To be eligible, patients had to meet the criteria of having received two series of treatments including undergoing at least two months of Beva treatment, aged 18 to 80 years, having a histologically proven GBM (except anaplastic astrocytoma and anaplastic oligodendroglioma), having available contrast-enhanced pre- and postoperative magnetic resonance imaging (MRI) scans, and a presystemic treatment complete blood count and blood chemistry tests. The exclusion criteria were patients who were not in follow-up or who showed other inflammatory conditions including heart failure, liver cirrhosis, or end-stage renal disease before initiating systemic treatment.

All eligible patients initially underwent neurosurgical tumor extirpation with the end goal of maximal safe resection, if judged appropriate. Following the neurosurgical intervention, three-dimensional conformal RT or simultaneous integrated boost intensity-modulated RT to a total dose of 60 or $70 \mathrm{~Gy}$ (2.0 or $2.33 \mathrm{~Gy} / \mathrm{fx}$, five days a week) over six weeks was delivered by using linear accelerators. Concurrent TMZ $\left(75 \mathrm{mg} / \mathrm{m}^{2}\right.$, seven days a week) was administered from the first until the last day of RT. All patients received standard pneumocystis jirovecii prophylaxis with trimethoprim-sulfamethoxazole during the concurrent chemoradiotherapy phase. In the adjuvant phase, patients received up to 12 cycles of maintenance TMZ (150 or $200 \mathrm{mg} / \mathrm{m}^{2} / \mathrm{d}$ ) for five days every 28 days. In the first-line treatment, TMZ (150 or $200 \mathrm{mg} / \mathrm{m}^{2}$ / d) for five days every 28 days treatment was continued until progression or intolerance in patients who were not suitable for surgery and RT after progression and who progressed six months after adjuvant therapy. Beva (10 mg/Kg) for every two weeks of treatment was continued until progression in the second-line treatment. If there were no symptoms, the patients were followed every three months with a gadolinium-enhanced MRI. Patients with symptoms were evaluated immediately.

Values for NLR, PLR, SIII, and CAR were calculated. Blood samples were obtained before the initial treatment to measure levels ofCRP (mg/dL), albumin ( $\mathrm{g} / \mathrm{L})$, and hemoglobin ( $\mathrm{Hb})$.

White blood cells (WBC), neutrophil, lymphocyte, and platelet (PIt) counts were also determined. NLR and PLR were defined as absolute neutrophil count, and platelet counts were divided by the total lymphocyte count. SIII was calculated with the formula '(neutrophils $\times$ platelets) /lymphocytes.'

Statistical data were obtained using SPSS for Windows, Version 24.0 (SPSS Inc., Chicago, IL, USA). Qualitative variables were described by frequencies and percentages, continuous and ordinal variables by mean \pm S.D., and median and interquartile ranges (IQRs). First, the Kolmogorov-Smirnov test was applied to determine whether the data were in the normal range of distribution. The Pearson $\chi 2$ test was used to compare qualitative variables. The characteristics of patients were evaluated with descriptive analysis. ROC analysis was used to determine the cut-off values of inflammation markers. Survival analysis was performed by means of Kaplan-Meier survival curves and the logrank test. Univariate and multivariate Cox proportional hazard models were used to identify predictors of overall survival. Hazard ratios (HRs) with $95 \%$ confidence intervals (Cls) were used to quantify the indexes estimating the survival. Hazard ratios of $>1.0$ indicated an increased likelihood of death. A twosided $p$-value of $<0.05$ was deemed statistically significant.

\section{RESULTS}

The clinicopathological characteristics of the patients are shown in Table I.

A total of 107 patients with GBM were identified in the institutional database. Fifty-eight (54.2\%) patients were males, and $49(45.8 \%)$ patients were females. The median age of the patients was $47.2 \pm 12.1$ years $[<50$ years patients $(54 / 107$, 50.5\%)]. Eighty-two (76.6\%) patients' ECOG PS was $0-1$ at the time of diagnosis. The other patients' ECOGPS was 25 (23.4\%). The most common localisations were the frontal lobe, 32 (29.9\%); the temporal lobe, 30 (28.0\%); the parietal lobe, 22 (20.6\%); and others, 23 (21.5\%). Primary GBM developed in 95 (88.8\%) patients, and GBM secondary to low-grade glioma developed in 12 (11.2\%) patients. Ki-67 was $\leq 20 \%$ in 61 patients ( $57 \%$ ), and $\mathrm{Ki}-67$ was $>20 \%$ in 46 patients ( $43 \%)$. P53 mutation was detected in 54 patients $(50.5 \%)$. IDH mutation was detected in 23 patients ( $25 \%$ ). Surgery was performed on 94 patients. Total excision was performed in 73 patients (77.7\%) and subtotal excision in 21 patients (22.3\%). All of the patients we evaluated received RT. While nine of these patients (8.4\%) received RT alone, 98 patients (91.6\%) received TMZ plus RT. One hundred five patients $(98.1 \%)$ received adjuvant TMZ after chemoradiotherapy. The median duration of the use of TMZ was six months (IQR 25-75: 2-24). After progression, 16 of the patients (15\%) received re-TMZ treatment and used it for a median of five months (IQR 25-75: 2 to 10 ). 
Table I: Demographic features and tumor characteristics of the patients.

\begin{tabular}{|c|c|c|c|}
\hline $\begin{array}{l}\text { Gender } \\
\text { Female } \\
\text { Male }\end{array}$ & $\begin{array}{l}49 / 107(45.8 \%) \\
58 / 107(54.2 \%)\end{array}$ & Age (mean $\pm s d)$ & $47.2 \pm 12.1$ \\
\hline $\begin{array}{l}\text { Age } \\
\qquad \begin{array}{r}\leq 50 \\
>50\end{array}\end{array}$ & $\begin{array}{l}54 / 107(50.5 \%) \\
53 / 107(49.5 \%)\end{array}$ & $\begin{array}{c}\text { ECOG PS } \\
0-1 \\
2+\end{array}$ & $\begin{array}{l}82 / 107(76.6 \%) \\
25 / 107(23.4 \%)\end{array}$ \\
\hline $\begin{array}{l}\text { Tumor localisation } \\
\text { Frontal } \\
\text { Temporal } \\
\text { Parietal } \\
\text { Others } \\
\end{array}$ & $\begin{array}{c}32 / 107(29.9 \%) \\
30 / 107(28 \%) \\
22 / 107(20.6 \%) \\
23 / 107(21.5 \%)\end{array}$ & $\begin{array}{l}\text { Type of surgery } \\
\text { Complete resection } \\
\text { Partial resection }\end{array}$ & $\begin{array}{l}73 / 94(77.7 \%) \\
21 / 94(22.3 \%)\end{array}$ \\
\hline $\begin{array}{r}\text { Ki } 67 \\
\leq 20 \\
>20\end{array}$ & $\begin{array}{l}61 / 107(57 \%) \\
46 / 107(43 \%) \\
\end{array}$ & $\begin{array}{l}\text { P53 status } \\
\text { Mutated } \\
\text { Non mutated }\end{array}$ & $\begin{array}{l}54 / 107(50.5 \%) \\
53 / 107(49.5 \%) \\
\end{array}$ \\
\hline $\begin{array}{l}\text { IDH-1 status } \\
\text { Mutated } \\
\text { Non-mutated }\end{array}$ & $\begin{array}{l}23 / 92(25 \%) \\
69 / 92(75 \%) \\
\end{array}$ & $\begin{array}{l}\text { First line treatment } \\
\text { RT } \\
\text { RT+Temozolamid }\end{array}$ & $\begin{array}{c}9 / 107(8.4 \%) \\
98 / 107(91.6 \%) \\
\end{array}$ \\
\hline $\begin{array}{l}\text { Origin } \\
\text { Primer GBM } \\
\text { Seconder GBM }\end{array}$ & $\begin{array}{l}95 / 107(88.8 \%) \\
12 / 107(11.2 \%)\end{array}$ & $\begin{array}{l}\text { Second line Temozolamid } \\
\text { Present } \\
\text { Absent }\end{array}$ & $\begin{array}{l}16 / 107(15 \%) \\
91 / 107(85 \%)\end{array}$ \\
\hline $\begin{array}{l}\text { Gamma knife } \\
\text { Present } \\
\text { Absent }\end{array}$ & $\begin{array}{l}23 / 107(21.5 \%) \\
84 / 107(78.5 \%)\end{array}$ & $\begin{array}{l}\text { Adjuvant Temozolamid } \\
\text { Present } \\
\text { Absent }\end{array}$ & $\begin{array}{c}105 / 107(98.1 \%) \\
2 / 107(1.9 \%)\end{array}$ \\
\hline
\end{tabular}

Table II: Prognostic factors of overall survival with bevacizumab treatment.

\begin{tabular}{|c|c|c|c|c|c|}
\hline 10y & (11 & $\begin{array}{l}\text { Univariate analysis } \\
\text { HR (\%95 CI) }\end{array}$ & p-value & $\begin{array}{l}\text { Multivariate analysis } \\
\text { HR }(\% 95 \mathrm{Cl})\end{array}$ & p-value \\
\hline Gender & $\begin{array}{l}\text { Male } \\
\text { Female }\end{array}$ & $\begin{array}{l}\text { Reference } \\
1.25(0.83-1.88)\end{array}$ & $p=0.289$ & & \\
\hline Age & $\begin{array}{l}\leq 50 \\
>50\end{array}$ & $\begin{array}{l}\text { Reference } \\
0.78(0.51-1.19)\end{array}$ & $P=0.246$ & & \\
\hline ECOGPS & $\begin{array}{l}0-1 \\
2+\end{array}$ & $\begin{array}{l}\text { Reference } \\
4.54(2.71-7.59)\end{array}$ & $P<0.001$ & $\begin{array}{l}\text { Reference } \\
3.74(2.20-6.38)\end{array}$ & $p<0.001$ \\
\hline Localisation & $\begin{array}{l}\text { Frontal } \\
\text { Parietal } \\
\text { Temporal } \\
\text { Others }\end{array}$ & $\begin{array}{l}\text { Reference } \\
0.77(0.42-1.39) \\
0.73(0.42-1.25) \\
1.03(0.59-1.80)\end{array}$ & $\begin{array}{l}p=0.384 \\
p=0.249 \\
p=0.926\end{array}$ & & \\
\hline Origin & $\begin{array}{l}\text { Primer GBM } \\
\text { Seconder GBM }\end{array}$ & $\begin{array}{l}\text { Reference } \\
1.78(0.94-3.36)\end{array}$ & $p=0.075$ & & \\
\hline Ki 67 & $\begin{array}{l}\leq 20 \% \\
>20 \%\end{array}$ & $\begin{array}{l}\text { Reference } \\
1.10(0.73-1.65)\end{array}$ & $p=0.655$ & & \\
\hline P53 mutation & $\begin{array}{l}\text { Absent } \\
\text { Present }\end{array}$ & $\begin{array}{l}\text { Reference } \\
1.02(0.68-1.54)\end{array}$ & $p=0.913$ & & \\
\hline IDH mutation & $\begin{array}{l}\text { Present } \\
\text { Absent }\end{array}$ & $\begin{array}{l}\text { Reference } \\
1.14(0.68-1.90)\end{array}$ & $p=0.629$ & & \\
\hline Surgery & $\begin{array}{l}\text { Total excision } \\
\text { Partial excision }\end{array}$ & $\begin{array}{l}\text { Reference } \\
1.39(0.83-2.33)\end{array}$ & $p=0.210$ & & \\
\hline $\operatorname{Re} T M Z$ & $\begin{array}{l}\text { Present } \\
\text { Absent }\end{array}$ & $\begin{array}{l}\text { Reference } \\
1.04(0.59-1.85)\end{array}$ & $p=0.890$ & & \\
\hline Gamma knife & $\begin{array}{l}\text { Present } \\
\text { Absent }\end{array}$ & $\begin{array}{l}\text { Reference } \\
1.48(0.87-2.51)\end{array}$ & $p=0.149$ & & \\
\hline CAR & $\begin{array}{l}\leq 1.32 \\
>1.32\end{array}$ & $\begin{array}{l}\text { Reference } \\
2.27(1.45-3.55)\end{array}$ & $P<0.001$ & $\begin{array}{l}\text { Reference } \\
1.92(1.21-3.05)\end{array}$ & $p=0.006$ \\
\hline NLR & $\begin{array}{l}\leq 2.9 \\
>2.9\end{array}$ & $\begin{array}{l}\text { Reference } \\
1.78(1.15-2.75)\end{array}$ & $P=0.009$ & $\begin{array}{l}\text { Reference } \\
1.38(0.87-2.17)\end{array}$ & $p=0.170$ \\
\hline PLR & $\begin{array}{l}\leq 159 \\
>159\end{array}$ & $\begin{array}{l}\text { Reference } \\
1.78(1.15-2.76)\end{array}$ & $P=0.010$ & $\begin{array}{l}\text { Reference } \\
1.66(1.07-2.59)\end{array}$ & $p=0.024$ \\
\hline SIII & $\begin{array}{l}\leq 785 \\
>785\end{array}$ & $\begin{array}{l}\text { Reference } \\
1.65(1.08-2.50)\end{array}$ & $P=0.020$ & $\begin{array}{l}\text { Reference } \\
0.96(0.53-1.73)\end{array}$ & $p=0.898$ \\
\hline
\end{tabular}

All patients who progressed after TMZ received Beva treatment. After the first progression, 23 (21.5\%) patients received gamma knife treatment.
Patients' inflammation parameters ( NLR, PLR, SIII, and CAR values) were recorded. ROC analysis was performed to determine the optimal predictive value of each parameter. Accord- 
ingly, NLR: 2.9, PLR: 159, SIII: 785, and CAR:1.32 were determined as cut-off values for predicting OS based on the areas under the curve (AUC) in the ROC analysis. CAR at 0.626 , had sensitivity of $67 \%$, and specificity of $71 \%(p=0.129)$; NLR at 0.725 had sensitivity of $67 \%$, and specificity of $79 \%$ $(p=0.007)$; PLR at 0.675 had sensitivity of $67 \%$, and specificity of $64 \%(p=0.036)$; and SIII at 0.685 , had sensitivity of $56 \%$, and specificity of $71 \%(p=0.026)$. NLR $>2.9$ (ORR: $51.4 \%$ vs. $48.6 \%, p=0.007$ ), PLR $>159$ (ORR: $54.3 \%$ vs. $45.7 \%, p=0.014$ ), and SIII >785 (ORR: $42.9 \%$ vs. $57.1 \%$, $p=0.007)$ were associated with a worse objective response rate (ORR). CAR >1.32 (ORR: $58.6 \%$ vs. $41.4 \%, p=0.363$ ) could not be demonstrated with ORR.

Survival analysis of patients treated with first line TMZ and second line Beva as systemic therapy was performed after Beva treatment started. All these patients were followed up with the best supportive care after Beva. The median followup after initiation of Beva was 8.4 (2.2-60.1 months) months. Patients' median OS after Beva initiation was 8.4 months (7.2-9.6, Cl 95\%), One-year OS was 29\%, and two-year OS was $12 \%$, respectively.

The effect of SIMs on the survival of patients treated with Beva was evaluated. The patients were divided into two groups: $C A R \leq 1.32$ and $>1.32$. Median survival was 11.9 months $(9.0-14.8$ months, $95 \% \mathrm{Cl})$ in the first group and 7.7 months $(6.4-8.9$ months, $95 \% \mathrm{Cl})$ in the second group. At the time of diagnosis, survival was significantly worse in patients with CAR $>1.32(p<0.001$, Figure 1$)$. The patients were divided into two groups: NLR $\leq 2.9$ and $>2.9$. The median OS was 9.8 months (6.8-12.7 months, $\mathrm{Cl} 95 \%$ ) in the first group and 8.1 months (7.2-9.0 months, $\mathrm{Cl} 95 \%$ ) in the second group. NLR $>2.9$ was found to be associated with a worse prognosis. ( $p=0.008$, Figure 1 ). The patients were divided into two groups: PLR $\leq 159$ and $>159$. Median survival was 9.5 months $(6.0-13.0$ months, $95 \% \mathrm{Cl})$ in the first group and 8.0 months $(6.5-9.5$ months, $95 \% \mathrm{Cl})$ in the second group. PLR> 159 was found to be associated with a worse prognosis ( $p=0.009$, Figure 1 ). The patients were divided into two groups: SIII $\leq 785$ and $>785$. Median survival was 9.4 months $(6.9-11.9$ months, $95 \% \mathrm{Cl})$ in the first group and eight months (6.9-9.1 months, $95 \% \mathrm{Cl}$ ) in the second group. SIII $>785$ was associated with a significantly poor prognosis, $p=0.018$, Figure 1 ).

Univariate and multivariate analyses were performed to assess the predictive value for OS in all patients. Univariate and multivariate Cox regression analyses are summarized in Table II.

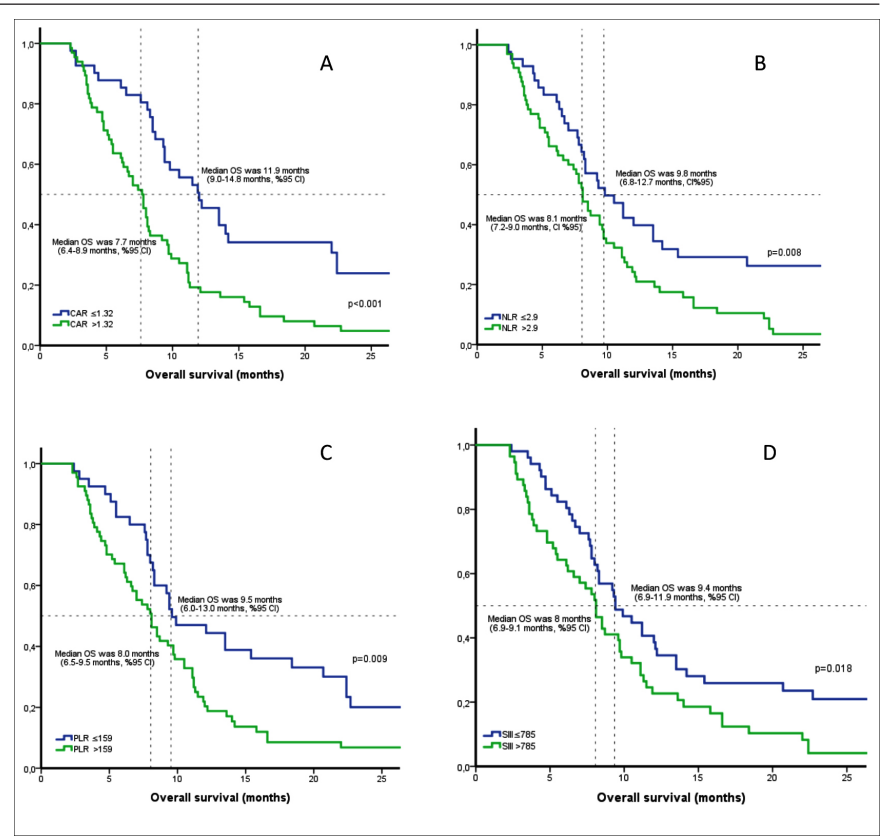

Figure 1: Kaplan-Meier curves according to SIMs of overall survival. (A) Kaplan-Meier curves according to CAR ( $\leq 1.32$ and $>1.32$ ), (B) Kaplan-Meier curves according to NLR $(\leq 2.9$ and $>2.9)$ of overall survival, (C) Kaplan-Meier curves according to PLR ( $\leq 159$ and $>159$ ) of overall survival, (D) Kaplan-Meier curves according to SIII ( $\leq 785$ and $>785$ ) of overall survival.

CAR: C-reactive protein albumin ratio, NLR: Neutrophil lymphocyte ratio, PLR: Platelet lymphocyte ratio, SIII: Systemic immune inflammation index, OS: Overall survival, $\mathrm{Cl}$ : Confidence interval).

The ECOGPS level of $\geq 2$ HR: $4.54(2.71-7.59) p<0.001$ was found to be associated with worse survival. Among the systemic inflammation parameters, CAR >1.32: HR: 2.27 (1.45-3.55) $p<0.001$, NLR >2.9: HR: $1.78(1.15-2.75) p=$ 0.009 , PLR >137: HR of $1.78(1.15-2.76), p=0.010$, and SIII $>785$ HR: $1.65(1.08-2.50) p=0.020$ were significantly associated with an increased risk of death. In multivariate Cox regression analysis, CAR >1.32 HR: 1.92 (1.21-3.05, $\mathrm{p}=$ 0.006 , PS $\geq 2$ HR: $3.74(2.20-6.38) p<0.001$ and PLR $>159$ HR: $1.66(1.07-2.59) p=0.024$ showed an increased risk of death.

\section{DISCUSSION}

In the present study, the predictive value of pretreatment CAR, PLR, NLR, and SIII was assessed in patients with GBM, who were treated by Beva. It was demonstrated that elevation in all of the inflammatory markers was correlated with poor OS, but only elevated CAR and PLR was found to be an independent predictive factor compared to NLR and SIII by multivariate analysis. The results consistently showed that increased CAR and PLR are significantly associated with a shorter OS and serves as an independent predictive factor for patients with GBM, who were treated by Beva.

This is the first study to show the predictive importance of traditional SIMs in the Beva treatment of GBM patients. Surgery and adjuvant radiotherapy plus TMZ have improved survival in GBM patients, but five-year OS is still at approxi- 
mately unacceptable levels, approximately $10 \% .{ }^{1}$ Although Beva contributed to PFS and quality of life in GBM patients, who progressed under TMZ treatment, it did not improve OS. ${ }^{7}$ However, as seen in this study, there may be patients who benefit from Beva treatment for a long time in some patient subgroups. Therefore, the markers that predict the treatment of Beva will contribute to individualized treatment.

The relationship between inflammation and the development of carcinogenesis in glioma patients was shown. ${ }^{13}$ Positive phase reactants (e.g., CRP, sedimentation, neutrophil, platelet) increase; while negative phase reactants, such as albumin, decrease using mediators released from necrotic cells in cancer tissue. ${ }^{14}$ Because of the decrease in albumin, while CRP increases, CAR is accepted as a rational method in cancer studies. ${ }^{15}$

CRP is an essential parameter for evaluating inflammation, but it may increase for many other reasons. Because of this, it is difficult to show its real importance in GBM patients. ${ }^{16}$ Although the decrease in albumin is associated with inflammation, it is also affected by the patient's nutritional state. Therefore, it is questionable to associate albumin's prognostic significance with inflammation only in GBM patients. ${ }^{17}$ The prognostic significance of the Glasgow prognostic score (GPS), which uses both CRP and albumin levels in GBM patients, has been demonstrated. ${ }^{18} \mathrm{~A}$ study showing the prognostic significance of CAR in GBM patients treated with adjuvant CRT was recently published. ${ }^{19}$

The prognostic and predictive significance of PLR could not be demonstrated in studies conducted with GBM patients. However, in this study, PLR was predictive and prognostic in GBM patients treated with Beva. ${ }^{20}$ The authors could not show the prognostic and predictive importance of SIII. Unlike this study, Topkan et al. showed that SIII is a prognostic factor in patients with GBM who received adjuvant therapy. ${ }^{21}$

NLR's predictive and prognostic significance could not be demonstrated while the studies that inspired this study showed the predictive importance of NLR in cancer types other than GBM treated with Beva. ${ }^{22,23}$ Bertaut et al. showed that an increase in the pre-treatment neutrophil count in GBM patients improved the Beva treatment response. ${ }^{24}$ Conversely, studies show that the increase in NLR is a poor prognostic factor. ${ }^{25}$ However, contrary to all these contradictory studies, the prognostic or predictive significance of the increase in NLR in GBM patients in this study could not be shown. More studies are needed in GBM patients treated with Beva to elucidate the importance of NLR.

The limitations of this study are its retrospective, single-centre design, the lack of MGMT result, and the relatively small number of patients.

\section{CONCLUSION}

The prognostic significance of SIMs and predictive impor- tance of CAR and PLR in GBM patients receiving second-line Beva treatment was demonstrated. If confirmed in larger prospective patient groups, CAR and PLR may contribute to the individualised treatment decision of GBM patients as an objective, cheap, and easy predictive tool.

\section{ETHICAL APPROVAL:}

The Clinical Research Ethics Committee of Bezmialem Vakif University approved the study, prior to initiation of the research work.

\section{PATIENTS' CONSENT:}

This study was retrospective and covered the years 2014-2019. It was often difficult to reach patients from the previous seven to eight years, because some of these patients did not have contact information, and some of them have died. For these reasons, informed consent could not be obtained from patients.

\section{CONFLICTS OF INTEREST:}

The authors declared no conflict of interest.

\section{AUTHORS' CONTRIBUTION:}

MB: Conception, design, supervision, resources, materials, data collection and processing, analysis and interpretation, literature search, writing manuscript, and critical review.

ATMS: Design, supervision, resources, materials, data collection and processing, literature search, writing manuscript, and critical review.

AIY, AT, HMT: Resources, materials, data collection, and processing.

TD: Conception, design, supervision, resources, materials, data collection and processing, literature search, writing manuscript, and critical review.

\section{REFERENCES}

1. Ostrom QT, Gittleman H, Xu J, Kromer C, Wolinsky Y, Kruchko $C$, et al. CBTRUS statistical report: primary brain and other central nervous system tumors diagnosed in the United States in 2009-2013. Neuro Oncol 2016; 18(suppl_5):v1-v75. doi:10.1093/neuonc/now207.

2. Li XZ, Li YB, Cao Y, Li PL, Liang B, Sun DJ, et al. Prognostic implications of resection extent for patients with glioblastoma multiforme: A meta-analysis. J Neurosurg Sci 2017; 61(6):631-9. doi:10.23736/S0390-5616.16.03619-5.

3. Barker FG 2nd, Chang SM, Gutin PH, Malec MK, McDermott MW, Prados MD, et al. Survival and functional status after resection of recurrent glioblastoma multiforme. Neurosurgery 1998; 42(4):709-23. doi:10.1097/00006 123-199804000-00013.

4. NCCN Guidelines, Central Nervous System Cancers. Version 2.2020-April 30, 2020.

5. Chaudhry IH, O'Donovan DG, Brenchley PE, Reid H, Roberts IS. Vascular endothelial growth factor expression correlates with tumour grade and vascularity in gliomas. Histopathology 2001; 39(4):409-15. doi:10.1046/j.13652559.2001.01230.x. 
6. Gatson NN, Chiocca EA, Kaur B. Anti-angiogenic gene therapy in the treatment of malignant gliomas. Neurosci Lett 2012; 527(2):62-70. doi:10.1016/j.neulet.2012.08.001

7. Friedman HS, Prados MD, Wen PY, Mikkelsen T, Schiff D, Abrey LE, et al. Bevacizumab alone and in combination with irinotecan in recurrent glioblastoma. J Clin Oncol 2009; 27(28):4733-40. doi:10.1200/JCO.2008.19.8721.

8. Tamura R, Tanaka T, Miyake K, Yoshida K, Sasaki H. Bevacizumab for malignant gliomas: current indications, mechanisms of action and resistance, and markers of response. Brain Tumor Pathol 2017; 34(2):62-77. doi:10.1007/s10014-017-0284-x.

9. Kanderi T, Gupta V. Glioblastoma Multiforme. In: StatPearls. Treasure Island (FL): StatPearls Publishing; July 6, 2020.

10. Demir T, Kostek O, Araz M, Sakin A, Aliyev A, Beşiroğlu M, et al. C-reactive protein to albumin ratio is an indicator of poor prognosis for patients with biliary tract cancer. EMJO 2020; 4(1) 65-70. doi: 10.14744/ejmo.2019.74396.

11. Brenner A, Friger M, Geffen DB, Kaisman-Elbaz T, Lavrenkov $K$. The prognostic value of the pretreatment neutrophil/lymphocyte ratio in patients with glioblastoma multiforme brain tumors: A retrospective cohort study of patients treated with combined modality surgery, radiation therapy, and temozolomide chemotherapy. Oncology 2019; 97(5): 255-263. doi:10.1159/000500926.

12. Tecchio C, Cassatella MA. Neutrophil-derived cytokines involved in physiological and pathological angiogenesis. Chem Immunol Allergy 2014; 99:123-37. doi:10.1159/000353358.

13. Galvão RP, Zong H. Inflammation and Gliomagenesis: Bi-Directional Communication at Early and Late Stages of Tumor Progression. Curr Pathobiol Rep 2013; 1(1):19-28. doi:10.1007/s40139-012-0006-3.

14. Tafani M, Di Vito M, Frati A, Pellegrini L, De Santis E, Giovanni S, et al. Pro-inflammatory gene expression in solid glioblastoma microenvironment and in hypoxic stem cells from human glioblastoma. J Neuroinflammation 2011; 8:32. doi:10.1186/1742-2094-8-32.

15. Demir T, Besiroglu M. Impact of inflammation markers on survival in patients with metastatic colorectal cancer. EJMI 2020; 4(4): 235-42.

16. Reynés G, Vila V, Martín M, Parada A, Fleitas T, Reganon E, et al. Circulating markers of angiogenesis, inflammation, and coagulation in patients with glioblastoma. J Neurooncol
2011; 102(1):35-41. doi:10.1007/s11060-010-0290-x.

17. Xu WZ, Li F, Xu ZK, Chen X, Sun B, Cao JW, et al. Preoperative albumin-to-globulin ratio and prognostic nutrition index predict prognosis for glioblastoma. Onco Targets Ther 2017; 10:725-33. doi:10.2147/OTT.S127441.

18. Topkan E, Selek U, Ozdemir Y, Yildirim BA, Guler OC, Ciner $\mathrm{F}$, et al. Prognostic value of the glasgow prognostic score for glioblastoma multiforme patients treated with radiotherapy and temozolomide. J Neurooncol 2018; 139(2):411-9. doi:10.1007/s11060-018-2879-4.

19. Topkan E, Besen AA, Mertsoylu H, Kucuk A, Pehlivan B, Selek U. Prognostic value of $C$-reactive protein to albumin ratio in glioblastoma multiforme patients treated with concurrent radiotherapy and temozolomide. Int J Inflam 2020; 2020:6947382. doi:10.1155/2020/6947382.

20. Yersal Ö, Odabaşi E, Özdemir Ö, Kemal Y. Prognostic significance of pre-treatment neutrophil-to-lymphocyte ratio and platelet-to-lymphocyte ratio in patients with glioblastoma. Mol Clin Oncol 2018; 9(4):453-8. doi:10.3892/mCo.2018.1695.

21. Topkan E, Besen AA, Ozdemir Y, Kucuk A, Mertsoylu H, Pehlivan $B$, et al. Prognostic value of pretreatment systemic immune-inflammation index in glioblastoma multiforme patients undergoing postneurosurgical radiotherapy plus concurrent and adjuvant temozolomide. Mediators Inflamm 2020; 2020:4392189. doi:10.1155/2020/4392189.

22. Passardi A, Scarpi E, Cavanna L, Dall'Agata M, Tassinari D, Leo $\mathrm{S}$, et al. Inflammatory indexes as predictors of prognosis and bevacizumab efficacy in patients with metastatic colorectal cancer. Oncotarget 2016; 7(22):33210-219. doi:10.18632/oncotarget.8901.

23. Botta C, Barbieri V, Ciliberto D, Rossi A, Rocco D, Addeo R, et al. Systemic inflammatory status at baseline predicts bevacizumab benefit in advanced non-small cell lung cancer patients. Cancer Biol Ther 2013; 14(6):469-75. doi:10.4161/ cbt. 24425.

24. Bertaut A, Truntzer C, Madkouri R, Kaderbhai CG, Derangere $\mathrm{V}$, Vincent J, et al. Blood baseline neutrophil count predicts bevacizumab efficacy in glioblastoma. Oncotarget 2016; 7(43):70948-958. doi:10.18632/oncotarget.10898.

25. Han S, Liu Y, Li Q, Li Z, Hou H, Wu A. Pre-treatment neutrophil-to-lymphocyte ratio is associated with neutrophil and T-cell infiltration and predicts clinical outcome in patients with glioblastoma. BMC Cancer 2015; 15:617. doi:10.1186/s12885-015-1629-7. 